\title{
Mobile Data Usage on Online Learning during Covid-19 Pandemic in Higher Education
}

\author{
https://doi.org/10.3991/ijim.v14i19.17499 \\ Edy Budiman \\ Universitas Mulawarman, Samarinda, Indonesia \\ edy.budimanefkti.unmul.ac.id
}

\begin{abstract}
The internet data assistance programs as one of the solutions from the higher education institutions in Indonesia to support students to online learning from home (OLFH) during the Covid-19 pandemic. In an effort to distribute targeted assistance, information on students' mobile data usage is required. This study aims to determine how much student data usage and its correlation toward meeting duration and feature usage. Collecting data using the Drive-test measurement methodology based on the perspectives of 80 students, we divided them into 4 groups. Statistical analysis and triangulation techniques were used to describe and validate the results with external data. The results explained that there was a correlation between the meeting duration with the feature usage toward the amount of mobile data usage, this shows that the length of meeting duration and the feature usage, the greater the data usage. And the values obtained $158.6 \mathrm{MB}-1036.9 \mathrm{MB}$ for the feature usage and without features in the range $134.22 \mathrm{MB}-674.22 \mathrm{MB}$. These results study is to strengthen the previous studies and become a reference for decision-makers and other needs. Particularly for support to distribution of internet assistance programs to students during OLFH due to the Covid-19 pandemic.
\end{abstract}

Keywords-Data usage, online learning, Covid-19

\section{$1 \quad$ Introduction}

\subsection{Applying the styles to an existing paper}

The coronavirus causes more people to work or learning from home (W-LFH). The long lockdown of the Coronavirus disease (Covid-19) pandemic has closed schools, higher education and other educational institutions in an effort to curb the spread of Covid-19 and cancel all teaching classes directly to virtual classrooms through online learning. The transition to learning to virtual is the culmination of efforts to prevent Covid-19 from spreading to university populations and to local communities.

The government's sudden decision to move the learning process from school to home creates problems. The unpreparedness of educational institutions in implementing online learning is the main factor in this chaos, even though the government actually provides an alternative solution in assessing students as a condition for gradua- 
tion-promotion of educational institutions in times of emergency. This transition of learning methods forces various parties to follow the path that can be taken so that learning can take place, and the choice is to use technology as an online learning medium.

The use of technology is actually not without problems, there are many factors that challenge the effectiveness of online learning such as the lack of knowledge and skills of teachers about using devices[1], [2], [3] the use of online learning or learning management systems (LMS)[4], [5], [6], internet network availability [7], network access costs [8], and etc. Moreover, since the implementation of the social distancing policy have an impact on many aspects of life, and economic issues have the most impact.

Initiatives of several local governments and higher education institutions in Indonesia. In an effort to reduce the budget for the use of online learning, is to provide free internet packages to students during the Covid-19 pandemic OLFH. The internet data assistance program is distributed to student smartphones every month with the same internet package value. However, the needs of each user are different from one another. This program is considered less objective and disproportionate in its distribution to beneficiaries (students). Some information is needed such as; the amount of internet usage, the number of courses, and meeting durations, including students' economic abilities.

This study aims to determine how much student data usage and its correlation toward meeting duration and feature usage. Collecting data using the Drive-test measurement methodology using bandwidth monitoring tools for incoming and outgoing based on the perspectives of 80 students, we divided them into 4 groups. Data analysis technique used descriptive statistical analysis, Pearson's bivariate correlation analysis and triangulation techniques.

The descriptive analysis used for describing the measurement data based on the quality of the experience (QoE) of the participants' perceptions[9]. And Pearson's bivariate correlation analysis test is used to see if there is a correlation between parameters on the amount of data usage.

Measurement of Zoom's usage is previously discussed by Tyler Abbott [10] and Nathan Snodgrass [11], who tested Zoom with 15 participants in a meeting. Our study used 80 participants who were divided into four group learning scenarios with different meeting duration and features.

The study results contribute to decision-makers in supporting the management of internet data package assistance programs to students for OLFH due Covid-19 pandemic.

\section{$2 \quad$ Material and Methods}

\subsection{Zoom's data usage and system requirements}

There are several factors that affect the how much Zoom's data usage, including; System requirements (network connection status and availability), streaming video quality, time duration and the number of participants, and Zoom features. As stated in 
the official support Zoom help centre[12], describes the device requirements for uses Zoom. These requirements are as presented in "Table 1".

Table 1. Zoom's requirements system[12]

\begin{tabular}{|c|c|}
\hline Item name & Specifications \\
\hline Bandwidth & $\begin{array}{l}\text { Bandwidth requirements: } \\
\text { For group video calling (classroom): } \\
800 \mathrm{kbps} / 1.0 \mathrm{Mbps} \text { (up/down) for high quality video } \\
\text { For gallery view and/or } 720 \mathrm{p} \text { HD video: } 1.5 \mathrm{Mbps} / 1.5 \mathrm{Mbps} \text { (up/down) } \\
\text { For screen sharing only: } 50-75 \mathrm{kbps} \\
\text { For screen sharing with video thumbnail: } 50-150 \mathrm{kbps} \\
\text { For audio VoiP: } 60-80 \mathrm{kbps} \\
\text { For Zoom Phone: } 60-100 \mathrm{kbps}\end{array}$ \\
\hline Internet connection & with $3 \mathrm{G}-4 \mathrm{G}$ or LTE technology \\
\hline Devices & $\begin{array}{l}\text { Connect with anyone on Android, other mobile devices, Mac, iOS, Zoom- } \\
\text { Presence }\end{array}$ \\
\hline
\end{tabular}

Information regarding network availability in the test area is carried out periodically and systematically on several previous studies by the author[13], [14], [15] reviews and general network performance evaluations are available for Zoom cloud meetings.

Related to the issue of Zoom data usage, Tyler Abbott [10], reveals that Zoom can be a real data problem. The measurement results show that for group meetings, Zoom spends between $450 \mathrm{MB}-1.2 \mathrm{~GB}$ per hour of download, and 360MB - 1.2GB per hour for upload. The total usage between $810 \mathrm{MB}$ - 2.4GB per hour[10]. Furthermore, Nathan Snodgrass[10] explained that the zoom quality depends on the client's internet access to work and for meetings can consume a lot of the available bandwidth[10].

\subsection{Research approach}

The research was conducted using qualitative and quantitative approaches. A qualitative approach through literature studies from several previous studies that carried out the same activity and to find out which factors affect how much Zoom's data usage. Furthermore, these factors are determined as the required parameters which are collected through measurement data to the 1stacademic year students in the undergraduate informatics program in one of the higher education institutions in Indonesia. The number of the sample (students) surveyed is presented in "Table 2".

Table 2. Survey sample and scenarios set

\begin{tabular}{|l|c|c|c|c|c|}
\hline \multirow{3}{*}{ User } & \multirow{2}{*}{ Quantity } & \multicolumn{2}{|c|}{ Features } & \multirow{2}{*}{ Meetings group } & Course duration (minute) \\
\cline { 2 - 5 } & & Video & Audio & & \multirow{2}{*}{ \pm 40} \\
\hline \multirow{4}{*}{ Students } & 20 & on & on & A & \multirow{2}{*}{ \pm 60} \\
\cline { 2 - 5 } & 20 & off & off & B & \\
\cline { 2 - 5 } & 20 & off & off & C & \\
\cline { 2 - 5 } & 20 & on & on & D & \\
\hline Total & 80 & & & & \\
\hline
\end{tabular}


There are 80 students were taken as participants, divided into 4 groups (A, B, C and D) with different sets of scenarios ("see Table 2"). Scenarios for using the Zoom feature (on/off) and meeting duration.

\subsection{Measurement methodology and equipment}

The data collection method uses the Drive-test measurement methodology, which collects information on the amount of student data usage. The measurement locations are in several areas in East Kalimantan Province, Indonesia, in each student's house during the Covid-19 pandemic. The measuring equipment used as shown in "Table 3".

Table 3. Measurement Equipment

\begin{tabular}{|l|l|}
\hline \multicolumn{1}{|c|}{ Equipment } & \multicolumn{1}{c|}{ Remarks } \\
\hline GlassWire data usage monitor Tools. & $\begin{array}{l}\text { the app to monitor mobile data usage, data limits, and WiFi network } \\
\text { activity[16] from url: https://www.glasswire.com }\end{array}$ \\
\hline Zoom Cloud Meetings & version 5.2.1 from url: https://zoom.us \\
\hline Mobile device & $\begin{array}{l}\text { devices used by participants (students)during online learning } \\
\text { (Zoom) }\end{array}$ \\
\hline
\end{tabular}

\subsection{Variable analysis}

The variables of this study are several factors that affect the amount of data usage during OLFH. These factors become parameters in measurement. These parameters are presented in "Table 4".

Table 4. Variable analysis (parameters)

\begin{tabular}{|c|l|l|l|}
\hline Variable & \multicolumn{2}{|c|}{ Remarks } & \multicolumn{1}{c|}{ Description } \\
\hline \multirow{2}{*}{ Zoom data usage } & Incoming & Bandwidth usage \\
\cline { 2 - 3 } & Outcoming & $\begin{array}{l}\text { The amount of data consumption read-recorded } \\
\text { on the device after the Zoom meeting is over. }\end{array}$ \\
\hline Meeting duration & 40 & Minutes & $\begin{array}{l}\text { The meeting duration was set for 40 minutes and } \\
60 \text { minutes with different group scenarios. }\end{array}$ \\
\hline
\end{tabular}

\subsection{Data analysis technique}

Data analysis used descriptive statistics and Pearson's bivariate correlation analysis[17]. Descriptive analysis is used to describe the results of measuring participants' perceptions, including validity testing. Pearson's bivariate correlation analysis test was used to see whether there was a correlation between variables (meeting duration and feature usage) on the amount of mobile data usage.

Additional analysis using triangulation techniques. Triangulation analysis study in the discussion section, this technique analysis to tests the measurement results by comparing the results (to find equations) with external data from empirical facts in the field or previous research studies. 


\section{Results}

The initial stage of the measurement result analysis is the validity test. The validity test using the Pearson Product Moment Correlation will correlate the respective measurement results (item scores) download and upload with the total value. If the value of $r$ count $>r$ table, then the item as stated is valid. The results of the validity test are shown in "Table 5".

Table 5. Validity testing: uses Pearson product moment

\begin{tabular}{|l|l|c|c|c|l|}
\hline \multicolumn{1}{|c|}{$\mathbf{N = 8 0}$} & Incoming & Outgoing & Total & \multicolumn{1}{|c|}{$\begin{array}{c}\text { Sig. }(\mathbf{2} \text {-tailed) } \\
\mathbf{0 . 0 5}\end{array}$} \\
\hline \multirow{2}{*}{ Incoming } & Pearson Correlation & 1 & $.507 * *$ & $.973 * *$ & Valid \\
\cline { 2 - 6 } & Sig. (2-tailed) & & 0.000 & 0.000 & Valid \\
\hline \multirow{2}{*}{ Outgoing } & Pearson Correlation & $.507 * *$ & 1 & $.692 * *$ & Valid \\
\cline { 2 - 6 } & Sig. (2-tailed) & 0.000 & & 0.000 & Valid \\
\hline \multirow{2}{*}{ Total } & Pearson Correlation & $.973 * *$ & $.692 * *$ & 1 & Valid \\
\cline { 2 - 6 } & Sig. (2-tailed) & 0.000 & 0.000 & & Valid \\
\hline
\end{tabular}

**. Correlation is significant at the 0.01 level (2-tailed).

"Table $5 "$ shows the value by sig. (2-tailed) $=0.01(* *)$, where $\mathrm{N}=80$, the value of rtable $a=0.286$, obtained. because rcount $>$ rtable, $(0.507>0.286,0.692>0.286$, $0.973>0.286)$, the measurement results all item are stated valid.

\subsection{Measurement results}

Group A, in meeting group A, the measurement scenario is meeting duration is set to \pm 40 minutes, with a Zoom features status: video and audio sets are disabled (OFF) for 20 participants in the group A. Statistical descriptions of the measurement results for group A meeting are seen in "Table 6".

Table 6. Statistical descriptions for group A

\begin{tabular}{|l|c|c|c|}
\hline \multicolumn{1}{|c|}{$\mathbf{N = \mathbf { 2 0 }}$} & Incoming $(\mathbf{M b})$ & Outgoing $(\mathbf{M b})$ & Total $(\mathbf{M b})$ \\
\hline Mean & 184.29 & 4.30 & 188.59 \\
\hline Median & 179.90 & 4.20 & 183.80 \\
\hline Mode & 127.7 & 4.8 & 134.22 \\
\hline Std. Dev & 42.15 & 1.64 & 41.60 \\
\hline Min. & 127.70 & 1.60 & 134.22 \\
\hline Max. & 253.40 & 7.40 & 258.40 \\
\hline
\end{tabular}




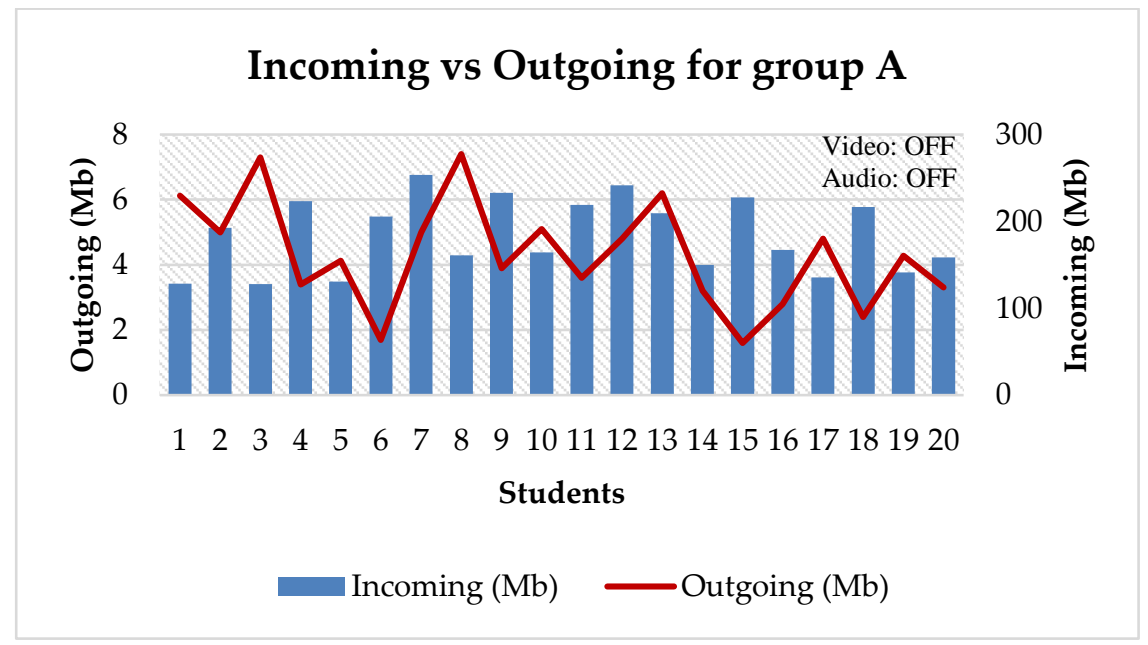

Fig. 1. Measurement results (incoming vs outgoing) for group A

Zoom's usage for group A in "Figure 1", when the meeting participants disabled video and audio features while learning, with the meeting duration is set to \pm 40 minutes. The measurement results obtained value range of $127.7 \mathrm{MB}-253.4 \mathrm{MB}$ for incoming and $1.6 \mathrm{MB}-7.4 \mathrm{Mb}$ for outgoing. Thus, the total usage for group $\mathrm{A}$ is in the range of $134.22 \mathrm{Mb}-258.40 \mathrm{Mb}$ per 40 minutes.

Group B, in meeting group B, the measurement scenario is meeting duration is set to \pm 40 minutes, with a Zoom features status: video and audio sets are enabled ON for 20 participants in the group B. Statistical descriptions of the measurement results for Group B meeting are seen in "Table 7".

Table 7. Statistical descriptions for group B

\begin{tabular}{|l|c|c|c|}
\hline \multicolumn{1}{|c|}{$\mathbf{N = \mathbf { 2 0 }}$} & Incoming $\mathbf{( M b )}$ & Outgoing $(\mathbf{M b})$ & Total $(\mathbf{M b})$ \\
\hline Mean & 249.38 & 51.64 & 301.03 \\
\hline Median & 258.05 & 54.25 & 311.15 \\
\hline Mode & 270.30 & 54.90 & 158.6 \\
\hline Std. Dev & 69.343 & 13.17 & 70.28 \\
\hline Min. & 121.60 & 30.80 & 158.60 \\
\hline Max. & 365.90 & 81.40 & 429.40 \\
\hline
\end{tabular}

The chart of measurement results (incoming vs outgoing) for group B is presented in "Figure 2". 


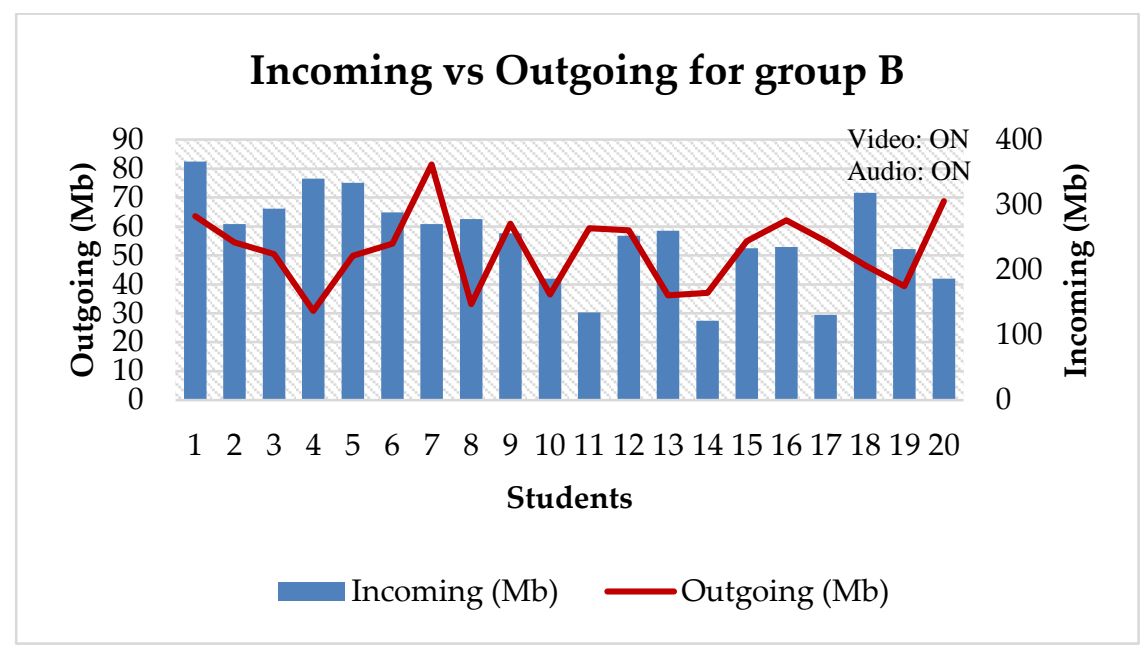

Fig. 2. Measurement results (incoming vs outgoing) for group B

Zoom's usage for group B in "Figure 2", when the meeting participants enabled video and audio features $(\mathrm{ON})$ while learning, with the meeting duration is set to \pm 40 minutes. The measurement results obtained value range of $121.6 \mathrm{MB}-365.9 \mathrm{MB}$ for incoming and $30.8 \mathrm{MB}-81.4 \mathrm{MB}$ for outgoing. Thus, the total usage for group $\mathrm{B}$ is in the range of $158.60 \mathrm{MB}-429.40 \mathrm{MB}$ per 40 minutes.

Group $\mathrm{C}$, in meeting group $\mathrm{C}$, the measurement scenario is meeting duration is set to \pm 60 minutes, with a Zoom features status: video and audio(mic) sets are disabled OFF for 20 participants in the group C. Statistical descriptions of the measurement results for Group C meeting are seen in "Table 8".

Table 8. Statistical descriptions for group C

\begin{tabular}{|l|c|c|c|}
\hline \multicolumn{1}{|c|}{$\mathbf{N = \mathbf { 2 0 }}$} & Incoming $(\mathbf{M b})$ & Outgoing $(\mathbf{M b})$ & Total $(\mathbf{M b})$ \\
\hline Mean & 558.64 & 8.78 & 567.42 \\
\hline Median & 563.55 & 7.15 & 568.85 \\
\hline Mode & 423.40 & 5.20 & 428.00 \\
\hline Std. Dev & 79.53 & 4.62 & 81.01 \\
\hline Min. & 423.40 & 4.60 & 428.00 \\
\hline Max. & 666.80 & 19.60 & 674.22 \\
\hline
\end{tabular}

The chart of measurement results (incoming vs outgoing) for group $\mathrm{C}$ is presented in "Figure 3". 


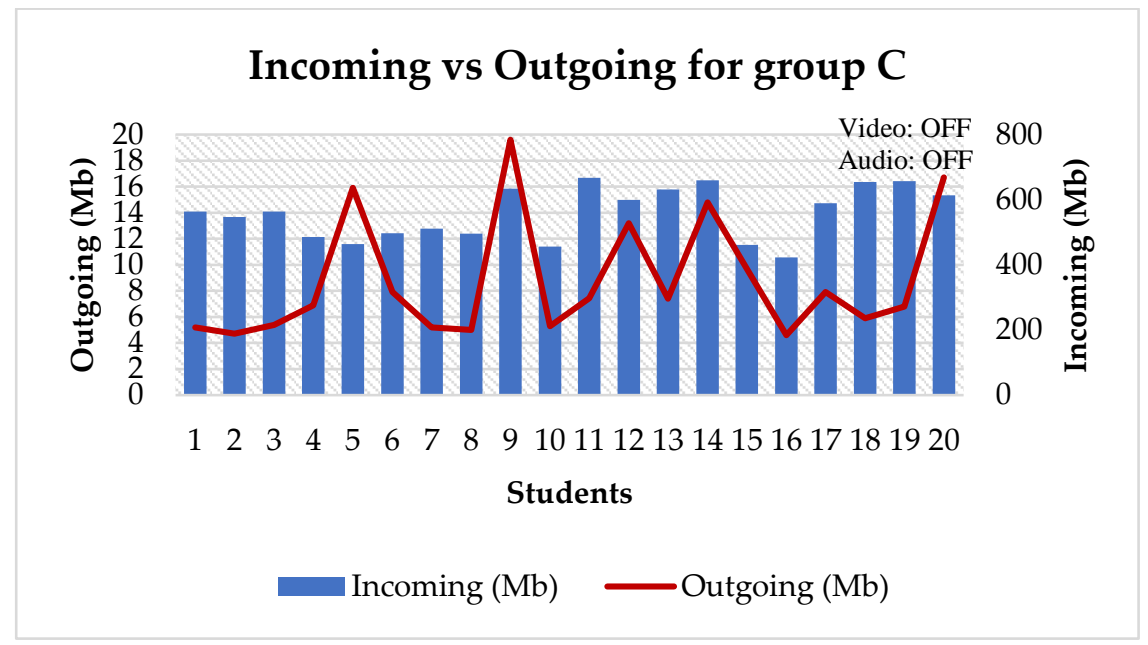

Fig. 3. Measurement results (incoming vs outgoing) for group C

Zoom's usage for group $\mathrm{C}$ in "Figure 3", when the meeting participants disabled video and audio features (Off) while learning, with the meeting duration is set to \pm 60 minutes. The measurement results obtained value range of $423.4 \mathrm{MB}-666.80 \mathrm{MB}$ for incoming and $4.6 \mathrm{MB}-19.6 \mathrm{MB}$ for outgoing. Thus, the total for group $\mathrm{C}$ is in the range of $428 \mathrm{MB}-674.22 \mathrm{MB}$ per 60 minutes.

Group D, in meeting group $\mathrm{D}$, the measurement scenario is meeting duration is set to \pm 60 minutes, with a Zoom features status: video and audio(mic) sets are enabled ON for 20 participants in the group D. Statistical descriptions of the measurement results for Group D meeting are seen in "Table 9".

Table 9. Statistical descriptions for group D

\begin{tabular}{|l|c|c|c|}
\hline \multicolumn{1}{|c|}{$\mathbf{N = \mathbf { 2 0 }}$} & Incoming $(\mathbf{M b})$ & Outgoing $(\mathbf{M b})$ & $\begin{array}{c}\text { Total } \\
\mathbf{( M b )}\end{array}$ \\
\hline Mean & 667.07 & 155.48 & 819.31 \\
\hline Median & 670.00 & 134.82 & 834.85 \\
\hline Mode & 512.30 & 126.60 & 566.50 \\
\hline Std. Dev & 129.67 & 66.49 & 141.13 \\
\hline Min. & 463.68 & 95.34 & 566.50 \\
\hline Max. & 911.60 & 352.40 & 1036.90 \\
\hline
\end{tabular}




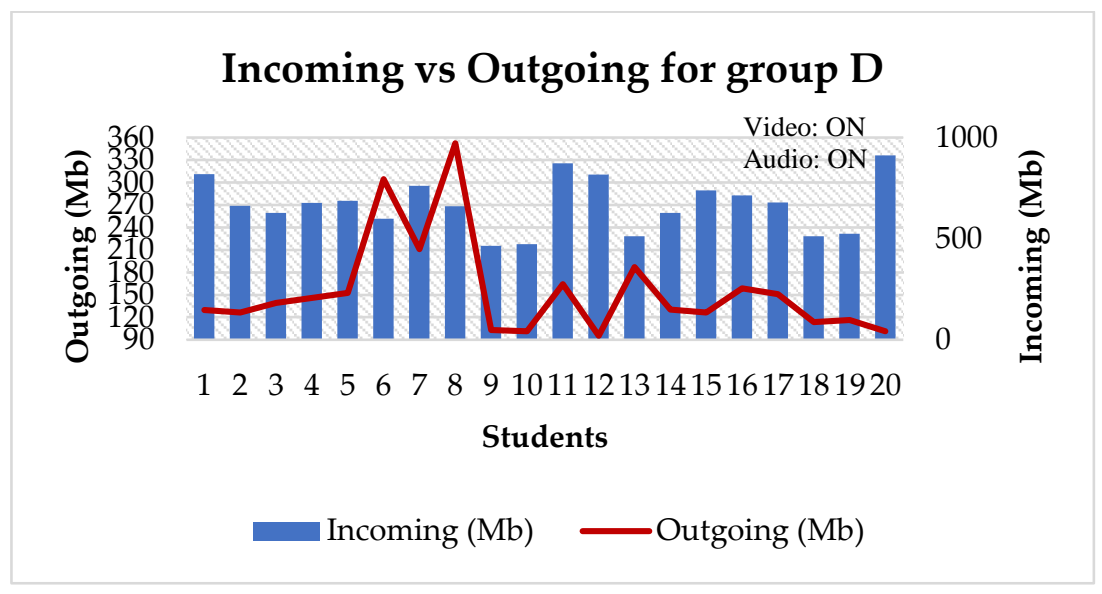

Fig. 4. Measurement results (incoming vs outgoing) for group D

Zoom's usage for group D in "Figure 4", when the meeting participants set enabled video and audio features (On) while learning, with the meeting duration is set to \pm 60 minutes. The measurement results obtained value range of 463.68MB - 911.60MB for incoming and $95.34 \mathrm{MB}-352.4 \mathrm{MB}$ for outgoing. Thus, the total for group $\mathrm{D}$ is in the range of $566.5 \mathrm{MB}-1036.90 \mathrm{MB}$ per 60 minutes.

\subsection{Analysis: Pearson's bivariate correlation}

The initial stage of analysis for group is to test the data using Pearson's bivariate correlation analysis. This correlation test aims to see whether there is a correlation between meeting duration and feature usage toward the amount of data usage.

1. Correlation between meeting duration toward the amount of data usage

The results of Pearson's bivariate correlation analysis between meeting duration and the amount of data usage in "Table 10" show that:

Table 10. Pearson's bivariate correlation: meeting duration and the amount of data usage

\begin{tabular}{|c|l|c|c|c|c|}
\hline \multirow{2}{*}{$\begin{array}{c}\text { Meeting } \\
\text { duration (minutes) }\end{array}$} & \multirow{2}{*}{ Parameter } & \multicolumn{2}{|c|}{$\begin{array}{c}\text { Total data usage } \\
\text { for 40 minutes }\end{array}$} & \multicolumn{2}{c|}{$\begin{array}{c}\text { Total data usage } \\
\text { for 60 minutes }\end{array}$} \\
\cline { 3 - 6 } & $\begin{array}{c}\text { Pearson } \\
\text { Correlation }\end{array}$ & Sig.(2-tailed) & Pearson Correlation & Sig. (2-tailed) \\
\hline \multirow{2}{*}{40} & Incoming & $.959^{* *}$ & 0.000 & $.382^{*}$ & 0.015 \\
\cline { 2 - 6 } & Outgoing & $.690^{* *}$ & 0.000 & $.786^{* *}$ & 0.000 \\
\hline \multirow{2}{*}{60} & Incoming & $.333^{*}$ & 0.036 & $.876^{* *}$ & 0.000 \\
\cline { 2 - 6 } & Outgoing & $.645^{* *}$ & 0.000 & $.783^{* *}$ & 0.000 \\
\hline
\end{tabular}

**. Correlation is significant at the 0.01 level (2-tailed).

*. Correlation is significant at the 0.05 level (2-tailed). 
Based on the Sig. value (2-tailed): If the value is Sig. (2-tailed) $<0.05$ then there is a correlation between parameters.

Based on Value $r$ count (Pearson Correlations): If value $r$ count $>r$ table $(\mathrm{N}=40, r$ table $=0.312$ ) then there is a correlation between parameters.

Based on the asterisk from SPSS: If there is an asterisk $(*)$ or $(* *)$ on the pearson correlation value then there is a correlation between the parameters analyzed.

Based on the 3 basic decisions of the Pearson bivariate correlation analysis, the results of the correlation in "Table 10" explain that: there are correlation between the meeting duration and the amount of data usage.

2. Correlation between feature usage toward the amount of data usage

The results of Pearson's bivariate correlation analysis in "Table 11" show that the feature usage has a correlation to the amount of data usage.

Table 11.

Pearson's bivariate correlation: features usage and the amount of data usage

\begin{tabular}{|l|l|c|c|c|c|}
\hline \multirow{2}{*}{ Feature usage } & \multirow{2}{*}{ Parameter } & \multicolumn{2}{|c|}{ Total data usagefor 40 minutes } & \multicolumn{2}{|c}{$\begin{array}{c}\text { Total data usage } \\
\text { for 60 minutes }\end{array}$} \\
\cline { 3 - 6 } & & Pearson Correlation & Sig. (2-tailed) & Pearson Correlation & Sig. (2-tailed) \\
\hline \multirow{2}{*}{ Disable (Off) } & Incoming & $1.000^{* *}$ & 0.000 & $.857^{* *}$ & 0.000 \\
\cline { 2 - 6 } & Outgoing & $.587 * *$ & 0.000 & $.481^{* *}$ & 0.002 \\
\hline \multirow{2}{*}{ Enable (On) } & Incoming & $.850^{* *}$ & 0.000 & $.980^{* *}$ & 0.000 \\
\cline { 2 - 6 } & Outgoing & $.650^{* *}$ & 0.000 & $.797 * *$ & 0.000 \\
\hline
\end{tabular}

**. Correlation is significant at the 0.01 level (2-tailed).

*. Correlation is significant at the 0.05 level (2-tailed).

\subsection{Summary data usage in online learning}

This section provides a summary of data usage per duration and per meeting. Based on the measurement results in section 3. A summary results presented in "Table $12 "$.

Table 12. A summary of data usage in online learning

\begin{tabular}{|c|c|c|c|c|c|c|}
\hline \multirow{2}{*}{ Group } & \multirow{2}{*}{ Feature usage } & \multirow{2}{*}{$\begin{array}{c}\text { Duration } \\
\text { (minutes) }\end{array}$} & \multicolumn{2}{c|}{ Total data usage (Mb) } & \multicolumn{2}{c|}{ Total Per minutes (Mb) } \\
\cline { 4 - 7 } & & Min & Max & Min & Max \\
\hline A & Off & 40 & 134.22 & 258.4 & 3.36 & 6.46 \\
\hline B & On & 40 & 158.6 & 429.4 & 3.97 & 10.74 \\
\hline C & Off & 60 & 428 & 674.22 & 7.13 & 11.24 \\
\hline D & On & 60 & 566.5 & 1036.9 & 9.44 & 17.28 \\
\hline
\end{tabular}

"Table 12" shows that time duration and feature usage affect the amount of data usage, this explains that with the feature usage range is between $158.6 \mathrm{MB}$ 1036.9MB, and without features the range is between $134.22 \mathrm{MB}-674.22 \mathrm{MB}$. A summary graph of data usage is shown in "Figure 5 ". 


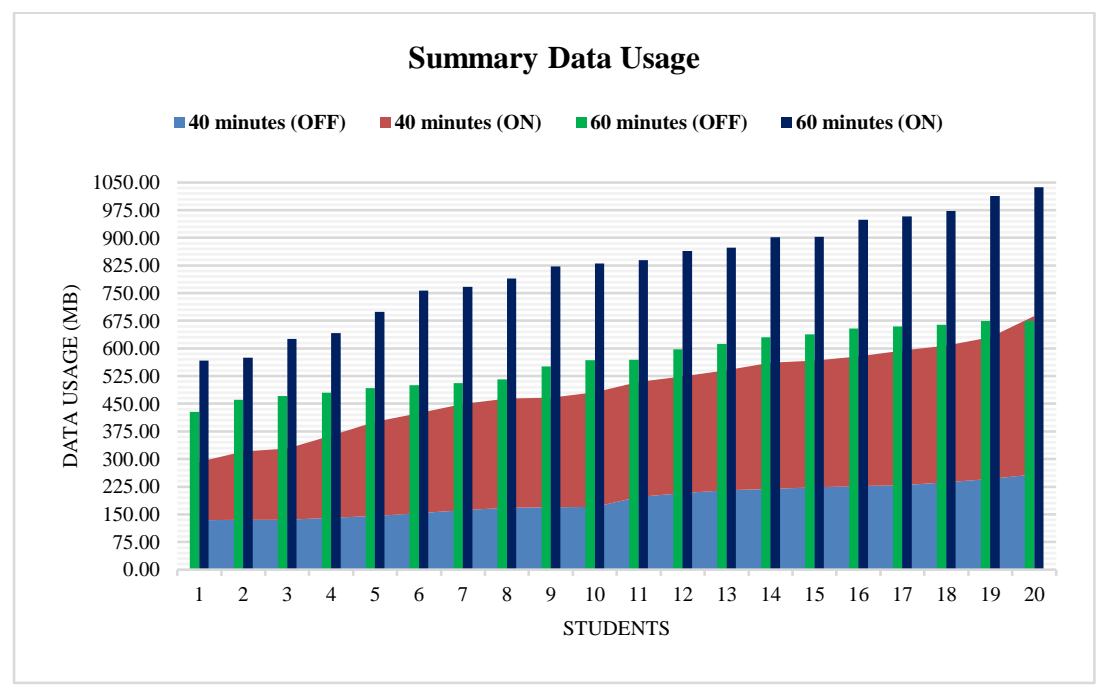

Fig. 5. Summary data usage.

\section{Discussion}

Triangulation data analysis study in this section of the discussion compares the measured data to find similarities, with the validity of external data from empirical facts in the field from previous research studies.

Measurements from Tyler Abbott[10] show that Zoom data usage for group meetings consumes between $450 \mathrm{MB}-1.2 \mathrm{~GB}$ per hour downloading data, and jumps to between $810 \mathrm{MB}$ and $2.4 \mathrm{~GB}$ per hour, or between $13.5 \mathrm{MB}$ and $40 \mathrm{MB}$ per minute. When reviewing our measurement results, that the data usage range for downloading is $463.68 \mathrm{MB}-911.6 \mathrm{MB}$ and the total usage is $566.5 \mathrm{MB}-1036.9 \mathrm{MB}$, then there are similarities in the range of measurement values. i.e. data usage per minute between 11.24 - 17.28MB.

In terms of internet data usage, in particular, at Zoom, many factors influence it. According to Lauren Hannula[18], There are a number of things that determine how much data is used when using Zoom at any given time, including connection speed, streaming quality, and features used. And in the findings of our study, that other factors are the time duration and the number of participants in the meeting, including the type of device used. Zoom app consume a lot of data, and we can be more innovative in new ways to take advantage of various models and other mobile learning technologies, such as the use of SMS technology[19] or through virtual environment mobile learning tools[20], leveraging social media such as WhatsApp groups for teaching and learning platforms[21], or simply being used for flexible access to $\mathrm{m}$-services for learning materials[22].

End of the discussion, that for the future study related the issue: the influence of the number of participants and the use of content with various types of presentation media files in learning will be interesting to study. 


\section{Conclusion}

With so many countries locked up and so many people working and learning from home, internet usage has increased significantly. The impact on the education sector, particularly in Higher Education raises many new problems in terms of the readiness of the owner (institution) and the ability of students to provide the internet for online learning. As the owner or organizer of the Higher Education institution, it is expected to be able to find solutions. And one of which is through the internet data assistance program for students. The distribution of internet data assistance programs is ideally determined by a number of factors, such as the amount of data usage, the duration of the meetings, the number of courses, and the economic ability of the students.

This study measures the amount of internet data usage in the Zoom application as a communication video for online learning during the Covid-19 pandemic.

The results of measurement and data analysis obtained the average value of student data usage between 11.24MB - 17.28MB per minute (enable-feature). This explains that the longer the meeting duration, the greater the data usage. We further explain that meeting duration issue and feature usage during learning via Zoom has a correlation toward the amount of data usage. In this regard, we propose to be able to manage learning activities that use video communication such as Zoom, with reducing feature usage, avoiding wasteful meeting duration, adjusting streaming quality, and including the selection of presentation content (learning materials) in Zoom.

These results study is to strengthen the previous researcher's studies and become a reference for decision-makers[23] for information on the amount of internet data use in online learning, and other needs specifically for support to distribution of internet assistance programs to educational actors (students, teachers, employees, etc.) during learning or work from home due to Covid-19 pandemic.

\section{Acknowledgment}

Thank you to the Dean of the Faculty of Engineering, Mulawarman University, Samarinda, East Kalimantan - Indonesia, who provided financially and support in research funding originating from State Higher Education Operational Assistance Fund (BOPTN) to improve lecturers' research quality. Thank you also to the Coordinator of the Undergraduate Informatics Program - Mulawarman University for all the support and assistance during the research.

\section{$7 \quad$ References}

[1] M. Kalogiannakis and S. Papadakis, "The Use of Developmentally Mobile Applications for Preparing Pre-Service Teachers to Promote STEM Activities in Preschool Classrooms," 2019. https://doi.org/10.4018/978-1-7998-1486-3.ch005

[2] M. Kalogiannakis and S. Papadakis, "Evaluating pre-service kindergarten teachers' intention to adopt and use tablets into teaching practice for natural sciences," International 
Journal of Mobile Learning and Organisation, 2019, https://doi.org/10.1504/ijmlo.2019.10 $\underline{016617 .}$.

[3] S. Papadakis, "Evaluating pre-service teachers' acceptance of mobile devices with regards to their age and gender: A case study in Greece," International Journal of Mobile Learning and Organisation, vol. 12, no. 4, pp. 336-352, 2018, https://doi.org/10.1504/ijmlo.2018.10 $\underline{013372 .}$.

[4] S. Papadakis, M. Kalogiannakis, E. Sifaki, and N. Vidakis, "Evaluating Moodle use via Smart Mobile Phones. A case study in a Greek University," EAI Endorsed Transactions on Creative Technologies, vol. 5, no. 16, p. 156382, 2018, doi: 10.4108/eai.10-42018.156382. https://doi.org/10.4108/eai.10-4-2018.156382

[5] M. Kalogiannakis and S. Papadakis, "Pre-Service Kindergarten Teachers Acceptance of " Scratchjr' As a Tool for Learning and Teaching," no. August, pp. 2-4, 2017.

[6] S. Papadakis and M. Kalogiannakis, "A Research Synthesis of the Real Value of SelfProclaimed Mobile Educational Applications for Young Children," 2019.

[7] E. Budiman, U. Hairah, Haeruddin, and A. Saudek, "Mobile Networks for Mobile Learning Tools," Journal of Telecommunication, Electronic and Computer Engineering, vol. 10, no. 1-4, pp. 47-52, 2018, [Online]. Available: journal.utem.edu.my/index.php/jtec/article/ view/3575.

[8] A. Posso, "Internet usage and educational outcomes among 15-year-old Australian students," International Journal of Communication, 2016.

[9] Rosmasari et al., "Usability Study of Student Academic Portal from a User's Perspective," in Proceedings - 2nd East Indonesia Conference on Computer and Information Technology: Internet of Things for Industry, EIConCIT 2018, 2018, pp. 108-113, https://doi.org/10. 1109/eiconcit.2018.8878618.

[10] T. Abbott, "How Much Data Does a Zoom Meeting Use?" www.reviews.org. https://www.reviews.org/internet-service/how-much-data-does-zoom-use/ .

[11] N. Snodgrass, “Zoom Quality and Data Usage," Extension Information Technology, NC State Extension, NC State University, 2020. https://eit.ces.ncsu.edu/2020/03/zoom-qualityand-data-usage/ (accessed Jul. 08, 2020).

[12] Zoom, "System requirements for Windows, macOS, and Linux," Zoom help center, 2020. https://support.zoom.us/hc/en-us/articles/201362023 (accessed Aug. 07, 2020).

[13] E. Budiman and O. Wicaksono, "Measuring quality of service for mobile internet services," in 2016 2nd International Conference on Science in Information Technology (ICSITech), Oct. 2016, pp. 300-305, https://doi.org/10.1109/icsitech.2016.7852652.

[14] E. Budiman, U. Haryaka, J. R. Watulingas, and F. Alameka, "Performance rate for implementation of mobile learning in network," 2017, https://doi.org/10.1109/eecsi.2017.82391 $\underline{87 .}$

[15] M. Taruk, E. Budiman, M. R. Rustam, Haviluddin, H. Azis, and H. J. Setyadi, "Quality of Service Voice over Internet Protocol in Mobile Instant Messaging," in Proceedings - 2nd East Indonesia Conference on Computer and Information Technology: Internet of Things for Industry, EIConCIT 2018, 2018, pp. 285-288, https://doi.org/10.1109/eiconcit.2018.88 $\underline{78574 .}$

[16] GlassWire Team, "GlassWire Data Usage Monitor," GlassWire Firewall for Android, 2020. https://www.glasswire.com/ (accessed Aug. 01, 2020).

[17] M. B. H. Ibrahim, M. T. Jufri, S. N. Alam, Zakaria, M. A. Akbar, and E. Budiman, "Statistical Analysis of Performance Goals Effect to Lecturer Work Achievement in Higher Education," 2018, https://doi.org/10.1109/eiconcit.2018.8878571.

[18] L. Hannula, "How Much Data Does Zoom Use?" WhistleOut. https://www.whistleout. com/Internet/Guides/zoom-video-call-data-use. 
[19] A. A. Ziden, M. Rosli, T. Gunasegaran, and S. N. Azizan, "Perceptions and experience in mobile learning via SMS: A case study of distance education students in a Malaysian public university," International Journal of Interactive Mobile Technologies, 2017, https://doi. org/10.3991/ijim.v11i1.6332.

[20] L. Brito Palma, V. Brito, J. Rosas, and P. Gil, "A virtual PLC environment for assisting automation teaching and learning," International Journal of Interactive Mobile Technologies, 2017, https://doi.org/10.3991/ijim.v11i5.7066.

[21] I. F. Rahmadi, "Whatsapp group for teaching and learning in indonesian higher education what's up?," International Journal of Interactive Mobile Technologies, vol. 14, no. 13, pp. 150-160, 2020, https://doi.org/10.3991/ijim.v14i13.14121.

[22] H. F. El-Sofany and N. El-Haggar, "The effectiveness of using mobile learning techniques to improve learning outcomes in higher education," International Journal of Interactive Mobile Technologies, 2020, https://doi.org/10.3991/ijim.v14i08.13125.

[23] E. Budiman, N. Dengen, Haviluddin, and W. Indrawan, "Integrated multi criteria decision making for a destitute problem," 2017, https://doi.org/10.1109/icsitech.2017.8257136.

\section{Author}

Edy Budiman is a lecturer at Informatics Study Program, Universitas Mulawarman, Indonesia. He is a member of the Institute of Electrical and Electronics Engineers (IEEE), member of Association for Computing Machinery (ACM) and a member of Asosiasi Perguruan Tinggi Ilmu Komputer (APTIKOM). His research interest includes Mobile Network, Performance and Apps.

Article submitted 2020-08-03. Resubmitted 2020-09-03. Final acceptance 2020-09-03. Final version published as submitted by the authors. 